\title{
Prevalence and Characteristics of Oral Squamous Cell Carcinoma in Fiji: A Retrospective Study
}

\author{
Mehwish Dean ${ }^{1}$, Ratu Osea Gavidi², Masoud Mohammadnezhad ${ }^{3}$ \& Richard D. Nair ${ }^{3}$ \\ ${ }^{1}$ Tavua Hospital, Tavua, Fiji \\ ${ }^{2}$ School of Dentistry and Oral Health, Fiji National University, Suva, Fiji \\ ${ }^{3}$ School of Public Health and Primary Care, Fiji National University, Suva, Fiji \\ Correspondence: Masoud Mohammadnezhad, Associate Professor in Public Health (Health Promotions) School of \\ Public Health and Primary Care, Fiji National University, Suva, Fiji. Tel: +679-97-26-127. E-mail: \\ masoud.m@fnu.ac.fj
}

Received: January 23, 2022 Accepted: February 21, 2022 Online Published: February 22, 2022

doi:10.5539/gjhs.v14n3p100 URL: https://doi.org/10.5539/gjhs.v14n3p100

\begin{abstract}
Background: Oral squamous cell carcinoma (OSCC) is malignant epithelial neoplasm that affects the oral cavity. Despite the large number of studies on OSCC in the literature, details on the demographic profile of these lesions in different populations are limited, especially amongst the Fijian population, thus this study aimed to determine the prevalence and characteristics of OSCC cases diagnosed from 2011 to 2015 at the Colonial War Memorial Hospital (CWMH), Suva, Fiji Islands.
\end{abstract}

Materials and Methods: A retrospective quantitative study was carried out at the CWMH Histology department looking at OSCC cases diagnosed from 2011-2015. All confirmed cases were included in the study and excluded cases were suspected cases that were pending diagnosis and children. An extraction sheet was used for data collection which was designed to meet the requirements of study finding. This data was entered in SPSS software and then analyzed using the simple analytical tool as bar graphs and tables.

Results: There were 74 OSCC cases diagnosed in the study period. The occurrence of OSCC cases over the 5-year period was fluctuant with the year 2013 recording the highest number of cases (24 cases, 32\%). During the reported period, more men suffered $(53$ cases, $72 \%$ ) from this condition with the tongue $(40 \%)$ being the commonest oral cancer site followed by the lip and vermillion border (28\%). Individuals in the 40 to 60 years' age group ( 35 cases, $47.3 \%$ ) were mostly affected with the I-taukei population (38 cases, $51.4 \%$ ) recording the highest occurrence of OSCC. The results show that, the common occurrence is the tongue $(40.5 \%)$ while the least presentation sight is Buccal mucosa/buccal sulcus area $(8.1 \%)$.

Conclusion: The study concluded that more men suffer from oral squamous cell carcinoma compared to woman and the ethnicity that was most affected was I-taukei population. More detailed record keeping and reporting of oral cancer is needed to help evaluate progress in controlling oral cancer in the Fiji Islands. This availability of geographic data would further assist the Ministry of Health of Fiji in data collection and planning of preventative activities

Keywords: epidemiological Characteristics, Fiji, oral squamous cell carcinoma, prevalence

\section{Introduction}

Every year, non-communicable diseases (NCDs) account for more than 36 million premature deaths (Hawley and McGarvey, 2015). Oral squamous cell carcinoma (OSCC) is the sixth most common cancer worldwide (Kempen et al., 2015). OSCC is one of the widespread multifactorial etiological epithelial malignancies associated with high mortality and morbidity. OSCC may typically occur completely new or from the commonly referred to pre-existing oral lesions as potentially malignant oral disorders (Feller \& Lemmer, 2012). Clinically, the lesion appears as an indolent ulcer with homogenous white patch in the early stages and is asymptomatic. Sometimes, there may be some discomfort and irritation (Rana et al., 2015; Gaitan-Cepeda, Peniche-Becerra, \& Quezada-Rivera, 2011).

In the advanced stage of the disease, patients present with a number of clinical presentations including ulceration 
or growth in the oral cavity, loosening of teeth, pain, malodour (halitosis), excessive salivation, bleeding, difficulty in speaking and swallowing, referred pain to the ear, swelling and ulceration of the face and neck swelling. The symptoms vary depending on the site of involvement (Muthu, Vaishnavi, \& Sivadas, 2018). The exact aetiology of OSCC is unknown however it has been strongly associated with tobacco use and alcohol consumption, human papilloma virus and some other risk factors (Bugshan \& Farooq, 2020; Mehrotra \&Yadav, 2006).

Leukoplakia is a homogenous white patch like lesion often advances to oral cancer is one of the major types of potentially malignant condition according to (Sridharan, Ramani, Patankar, \& Vijayaraghavan, 2019). Various parts of India, leukoplakia has a recorded incidence of 1.3-2.1 per 1000 individuals. Despite advancements in diagnosis and treatment over the decades, the disorder remains a concern for medical professionals with a 5 -year survival rate of about 45\% (Sridharan, Ramani, Patankar, \& Vijayaraghavan, 2019). The incidence of OSCC has been increasing in most countries around the world predominantly in South and Southeast Asia, West and East European, Caribbean and in the Pacific (Siakholak et al., 2016; Purwanto et al., 2019; Selvamani, Yamunadevi, Basandi, \& Madhushankari, 2015).

Prevalence of OSCC is increasing in Pacific Island Countries (PICs) such as Papua New Guinea and other Melanesian countries (Siakholak et al., 2016). It is important to report the occurrence of OSCC in Fiji that experiences different NCDs. In relevance to the population data of Fiji Gavidi et al., (2014); concluded that according to the annual age standardized ratio (ASR) for OSCC there were 13 per 1,000,000 persons compared to New Zealand population. This study was also a retrospective study based on Fijis OSCC prevalence in comparison to New Zealand whereby same methodology was used to extract data of Fiji between years 2000 and 2010 as the present study which reflects OSCC cases between 2011 and 2015. Despite the large number of studies on OSCC in the literature, details on the demographic profile of these lesions in different populations are limited, especially amongst the Fijian population. Therefore, this study aimed to determine prevalence and characteristics and of OSCC over a period of 5 years from 2011 to 2015 in Fiji.

\subsection{Materials and Methods}

\subsection{Study Design and Setting}

This quantitative retrospective study was conducted at Colonial War Memorial Hospital (CWMH) and data was collected from 2011 to 2015. CWMH is the major referral hospital in Fiji comprising of 22 wards in total. All oral pathological cases are referred to for the confirmation of diagnosis, according to the pathologist of CWMH over a phone conversation, approximately 2 cancer cases are diagnosed weekly and 1 to 2 oral cancer per month. In this regard, the data collected in this study can be approximated as a representative of the national data evincing an increase in the prevalence of occurrence of OSCC among all multiracial groups in Fiji. For exact values of cases per week diagnosis, this was not available on patient information system as well; as it is only updated from year 2013 onwards and most records in this study are missing from the server itself, however they are keeping the manual registers which was used to access all missing data. The ward number was informed by the sister-in charge via phone call.

\subsection{Study Population and Sample}

In this study the age distribution was chosen at 10 year interval to highlight the occurrence of OSCC in younger individuals which are often misdiagnosed thus inappropriately treated, if data is available for younger populations there would be more vigilance in screening and easier tracking of the patients five-year survival period and cancer stages depending upon the TNM (Tumor, Node, Metastasis) stage of cancer. The exclusion criteria include all those records which are not confirmed diagnosis of OSCC and are suspected lesions only.

The age distribution used in this study is at a 5 year interval which proves the hypothesis yet again proven by Gavidi et al., (2014) that OSCC occurrence in both genders in Fiji was very similar for most age groups and very infrequent from the 1st to 4 th decade of life; the age ratio increased in individuals from age 45 and over. Another reason for choosing age distribution at a 5 year interval was to highlight the occurrence of OSCC in younger individuals which are often misdiagnosed thus inappropriately treated, if data is available for younger populations there would be more vigilance in screening and easier tracking of the patients five-year survival period and cancer stages depending upon the TNM (Tumor, Node, Metastasis) stage of cancer.

\subsection{Data Collection}

All data was collected from the cancer registry and histopathology registers. All confirmed OSCC records between 2011-2015 was included in the study. The independent variables such as ethnic groups (I-taukei; Fijian of Indian decent; Fijians of other decent), gender (male and female) affected, age and location of lesion were included in the data. 


\subsection{Data Analysis}

Data was entered on Microsoft excel spread sheet and then imported to Statistical Package for Social Sciences (SPSS) version 24 to perform a descriptive statistical analysis to generate the graphs and tables. This method was seen as plausible in a case study whereby the same procedure was applied to a large quantity of data (Nair et al. 2021). Each recorded registry was assigned a code to de-identify patient information which was kept in sealed envelopes. Patients' information such as the location of cancer, age range diagnosed, ethnicity, gender and year of diagnosis was then entered into the excel spreadsheet.

\subsection{Ethical Approval}

Ethical approval was obtained from the Fiji National University- College of Medicine, Nursing \& Health Sciences Research \& Ethics Committee (CHREC), the Fiji National Health Research \& Ethics Committee (FNHREC) the Medical superintendent of CWMH and the head of Department of Histopathology at CWMH.

\section{Results}

Seventy-four cases of OSCC diagnosed at CWMH during the study period of 2011 to 2015 . The results reveal that around two thirds of OSCC cases were male population $(72 \%)$ and one third was female population $(28 \%)$. It was also shown that OSCC was mostly diagnosed in individuals of age group 40-60 (35, 47.3\%), that followed by the age group 60 and over $(31,41.9 \%)$. Also it was found that distribution of the cancer was almost fair amongst I-taukei (51.4\%) and Indo Fijian (44.6\%). the two larger ethnic populations of Fiji.

Table 1. Demographic features of patients with OSCC $(n=74)$

\begin{tabular}{lllllll}
\hline Variables & \multicolumn{5}{c}{ Year's n (\%) } \\
\cline { 2 - 7 } Gender & 2011 & 2012 & 2013 & 2014 & 2015 & Total \\
Male & $10(83)$ & $8(67)$ & $19(79)$ & $4(40)$ & $12(75)$ & $53(72)$ \\
Female & $2(17)$ & $4(33)$ & $5(21)$ & $6(60)$ & $4(25)$ & $21(28)$ \\
Total per year & $12(100)$ & $12(100)$ & $24(100)$ & $10(100)$ & $16(100)$ & $74(100)$ \\
\hline Age & & & & & & \\
$20-29$ & $0(0)$ & $2(16.66)$ & $1(4.16)$ & $0(0)$ & $0(0)$ & $3(4.05)$ \\
$30-39$ & $0(0)$ & $0(0)$ & $2(8.33)$ & $3(30)$ & $0(0)$ & $5(6.75)$ \\
$40-49$ & $6(50)$ & $4(33.3)$ & $5(20.8)$ & $1(10)$ & $1(6.25)$ & $17(22.9)$ \\
$50-59$ & $1(8.33)$ & $3(25)$ & $7(29.16)$ & $3(30)$ & $4(25)$ & $18(24.3)$ \\
$60-69$ & $4(33.3)$ & $2(16.66)$ & $6(25)$ & $0(0)$ & $3(18.75)$ & $15(20.27)$ \\
$70-79$ & $1(8.33)$ & $1(8.33)$ & $2(8.33)$ & $3(30)$ & $7(43.75)$ & $14(18.91)$ \\
$80-89$ & $0(0)$ & $0(0)$ & $1(4.16)$ & $0(0)$ & $1(6.25)$ & $2(2.70)$ \\
\hline Ethnicity & & & & & & \\
I-taukei & $7(58.3)$ & $7(41.7)$ & $12(50.0)$ & $4(40.0)$ & $8(50.0)$ & $38(51.4)$ \\
Indo Fijian & $5(41.7)$ & $4(33.3)$ & $12(50.0)$ & $6(60.0)$ & $6(37.5)$ & $33(44.6)$ \\
Fijians of other decent & $0(0)$ & $1(8.3)$ & $0(0)$ & $0(0)$ & $2(12.5)$ & $3(4.1)$ \\
\hline
\end{tabular}

Figure 1 shows the total number of cases diagnosed each year along the study period. The results show that, the confirmed cases of OSCC were same for years 2011 and 2012 (each 12 cases, $16.2 \%$ of total cases). There was a significant increase of diagnosed cases in 2013, cases was twice as much being 24 cases ( $32.4 \%$ of total cases) then fluctuated between 2014 (13.5\%) and 2015, 10 cases (13.5\%) and 16 cases (21.6\%); respectively. 


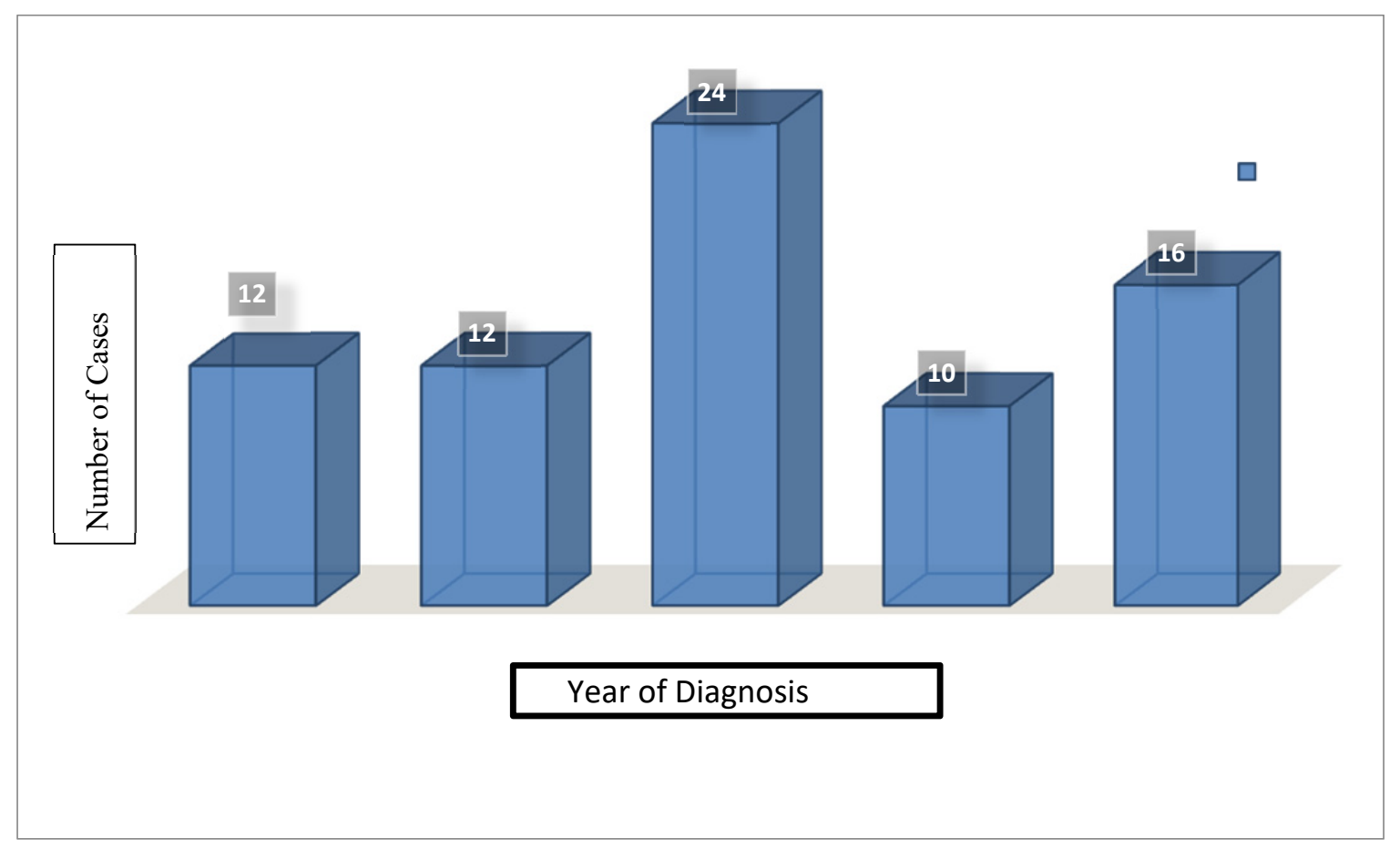

Figure 1. Frequency of OSCC cases diagnosed from 2011-2015

Table 2 shows the clinical characteristic of OSCC specifically its location of occurrence over the study period. The results show that, the common occurrence is the tongue (40.5\%) and lips and vermillion border of the lips (28.4\%). It is also noted that very least presentation sight is Buccal mucosa/buccal sulcus area (8.1\%), Floor of mouth/ventral tongue (10.8\%), and the soft palate and tonsilar area $(12.2 \%)$.

Table 2. Clinical characteristics of OSCC

\begin{tabular}{lllllll}
\hline \multirow{2}{*}{ Variables } & \multicolumn{5}{c}{ Year n (\%) } \\
\cline { 2 - 7 } & 2011 & 2012 & 2013 & 2014 & 2015 & Total \\
\hline Cancer Location & $7(58.3)$ & $3(25)$ & $12(50)$ & $5(50)$ & $3(18.8)$ & $30(40.5)$ \\
Tongue & $1(8.3)$ & $6(50)$ & $5(28.8)$ & $4(40)$ & $5(31.3)$ & $21(28.4)$ \\
Lips and vermilion boarder & $3(25)$ & $0(0)$ & $0(0)$ & $0(0)$ & $3(18.8)$ & $6(8.1)$ \\
Buccal mucosa/buccal sulcus & $1(8.3)$ & $2(16)$ & $2(8.3)$ & $0(0)$ & $6(18.8)$ & $8(10.8)$ \\
Floor of mouth/ventral tongue & $0(0)$ & $1(8.3)$ & $5(20.8)$ & $1(10)$ & $2(12.5)$ & $9(12.2)$ \\
Soft palate e/tonsil area & & & & & & \\
\hline
\end{tabular}

\section{Discussion}

There were 74 cases of OSCC diagnosed in CWMH during the 2011-2015 time period compared with 124 cases for the whole of Fiji Islands in the 2000-2010 time period (Gavidi et al., 2014). This suggests that there has been an increase in the average annual number of OSCC cases in Fiji since the 2000-2010 time period. There was a reduction in concurrence between 2014 and 2015 that could be correlated to early detection and diagnosis by the oral surgery team which was more strongly formed in 2013. However, during the study period the cases included were confirmed diagnosed cases only; pending diagnosis cases were excluded

The finds of this study revealed that males had more OSCC than females. This is an interesting finding since the previous study reported by Gavidi et al., (2014) showed equal distribution between both genders. Over the study period, it was noticed that oral squamous cell carcinoma was not dependent on gender or ethnicity. All ethnic groups in the study namely Itaukei and Fijian of Indian descent and Fijians of other origins were affected inclusive of both males and females. Lumukana and King, (2003) reported that amongst Solomon Island men, OSCC was 
attributed to have a high prevalence with a male to female ratio of 1:3 hence showing a male predilection of the disease.

In this study, individuals in the age group of 40-60 years were mostly affected with the itaukei (natives) population recording the highest occurrences (51.4\%), followed by Fijian of Indian descent (44.6\%) and the minority population of Fijians from others descent having the lowest occurrence (4.1\%). This suggests that ethnicity does not play a major role in the occurrence of the disease but the occurrence can be narrowed down to the practises by these ethnic groups in later studies. This is another interesting occurrence as middle aged individuals are reported to have the highest occurrence of the disease. OSCC occurrence in both genders in Fiji was very similar for most age groups and very infrequent from the $1^{\text {st }}$ to $4^{\text {th }}$ decade of life; the age ratio increased in individuals from age 45 and over.

Additionally, late stage of disease at diagnosis occurred for $100 \%$ for cancer of the base of the tongue, $90 \%$ for cancer of the gingiva and floor of the mouth, while early stages of disease occurred for $100 \%$ of cancer of the lip. This could be related to the cell structure of these locations intra-orally that makes it more prone to be affected as compared to other locations with highly keratinised cells; however more advanced screening such as TNM staging and risk factor identification of individual case presentation is required to reach a precise conclusion. In a study by Albuquerque et al., (2011) it was instituted that the lateral borders of the tongue were the most repeated carcinoma locations in both groups (drinking and smoking persons as well as nondrinking and non-smoking subjects). According to them, lateral border showed $59.7 \%$ and $40.3 \%$ in user and nonusers, respectively. In similar study by Falaki et al., (2011) 158 cases of OSCC was analysed and again it was found that the most mutual site of involvement was the tongue (66\%) and lateral border of the tongue. These studies and their results are similar to present study results as we also concluded tongue $40.5 \%$ to be the most common site affected

Cancers of the oral cavity have been reported to have a high mortality rate and despite the current advancement in treatment options, the situation has not improved. Five-year survival rates ranging from $30 \%$ to $80 \%$ have been reported from several parts of the world. Survival rates are lower in low and middle income countries in comparison to high income countries (Sargeran et al., 2008). A retrospective study carried out in the Spanish city of Cordoba from 1989 to 2005 reported that, of the 89 OSCC cases the 5- year survival rates were lowest (35-40\%) amongst those 61 to 70 years of age (Bolesina et al., 2007). The most frequent cancer location was in the tongue (26\%), followed by gum (23\%) and floor of the mouth (11\%). The highest mortality rate occurred for cancer of the base of the tongue, the gum and the floor of the mouth having the rates of; $100 \%, 88 \%$ and $85 \%$, respectively (Bolesina et al., 2007).

The observed 5-year survival rate in OSCC stage I was $75 \%$ whereas only $23 \%$ of the patients survived with Stage IV disease. In the study by Gavidi et al., (2014) that compared the incidence of OSCC in New Zealand and Fiji, 1916 cases of OSCC occurred in NZ in the 11-year study period and 124 in Fiji, 89\% and 93\% of all oral malignancies respectively. The annual age standardized incidence rate for New Zealand and Fiji was 4.2 and 1.3 per 100,000 individuals, respectively.

Nagler (2006) suggested that oral carcinogenesis of tobacco may be due, at the molecular level, to an interaction between the redox-active metals in saliva and the low reactive free radicals in cigarette smoke. The result may be that saliva loses its antioxidant capacity and instead becomes a potent pro-oxidant milieu. In addition, dehydrogenase oxidizes ethanol to acetaldehyde, which is cytotoxic and results in the production of free radicals and DNA hydroxylated bases that includes alcohol dehydrogenase type 3 genotypes which appear to predispose to OSCC.

Alcohol consumption was the most prevalent risk factor for oral cancer found in New Zealand, followed by tobacco (Gavidi et al., 2014). Given the high prevalence of these two risk factors and their synergistic effect, it becomes essential for doctors and dentists to encourage smoking cessation in smokers and to recommend judicious alcohol intake amongst heavy drinkers. Other factors include betel nut chewing together with smoking, impaired immune function, poor nutrition status and human papilloma virus infections. Chronic irritation from dentures were proved to be a modifying factor rather than an initiator of oral squamous cell carcinoma.

\section{Limitations}

The major limitations of the study were unavailability of detailed data and record keeping for individual case. Also no proper system of records was followed and the patient information system was only updated from 2013 and were missing a significant amount of data.

Manual counting of patients by over going the registers may have been subjected to human errors of overlooking any case. It was noted that many results were discussed over the phone call to practitioners and the exact diagnosis 
was not documented in the register thus these cases had to be excluded from total number of cases found. Suspected cases were also excluded as no record of follow ups were available to give exact diagnosis.

Another major limitation was time, the registers were only given for maximum of 2 hours three times a week and it was difficult to compile all data in sheets within the time frame, delayed response from the medical superintendent for release of registers added more to the gist of difficulties.

\section{Conclusion}

The study concluded that more men suffer from oral squamous cell carcinoma compared to woman and the ethnicity that was most affected was I-taukei population. More detailed record keeping and reporting of oral cancer is needed to help evaluate progress in controlling oral cancer in the Fiji Islands. Factors such as tumour size, location, bone involvement, skin involvement, lymphovascular and perineural invasion, invasive front grading, DNA-ploidy status and histopathology should be recorded when cancers are diagnosed to assess whether there is favourable trend towards earlier diagnosis and the prevention of oral cancer. The demographic, geographic and ethnic variations in the incidence plays important role especially for zone nurses to identify the hot spots for cases. In this study, the most affected ethnic group is the i-taukei population and the most common site affected is tongue second by lips and vermillion border.

\section{Recommendations}

The prognostic determination factors such as; presence or absence of metastasis, number and site of positive nodes, size of metastatic deposit, laterality of positive nodes, extra-capsular spread and post-operative nodal stage should be taken into consideration. This would assist in holistic management of such cases.

This availability of geographic data would further assist the Ministry of Health of Fiji in data collection and planning of preventative activities. More community awareness and primary screening outreach programs should be provided to the population of Fiji especially individuals in the fourth to fifth decade of their life.

\section{Competing Interests Statement}

The authors declare that there are no competing or potential conflicts of interest.

\section{References}

Albuquerque, R., López-López, J., Marí-Roig, A., Jané-Salas, E., Roselló-Llabrés, X., \& Santos, J. (2011). Oral tongue squamous cell carcinoma (OTSCC): alcohol and tobacco consumption versus non-consumption. A study in a Portuguese population. Brazilian Dental Journal, 22(6), 517-521. https://doi.org/10.1590/S0103-64402011000600013

Boring, C., Squires, T., Tong, T., \& Montgomery, S. (1994). Cancer statistics, 1994. CA: A Cancer Journal for Clinicians, 44(1), 7-26. https://doi.org/10.3322/canjclin.44.1.7

Bugshan, A., \& Farooq, I. (2020). Oral squamous cell carcinoma: metastasis, potentially associated malignant disorders, etiology and recent advancements in diagnosis. F1000research, 9, 229. https://doi.org/10.12688/f1000research.22941.1

Cancers of the Oral Mucosa: Background, Pathophysiology, Etiology. (2022). Retrieved 23 January 2022, from http://emedicine.medscape.com/article/1075729-overview.

Falaki, F., Dalirsani, Z., Pakfetrat, A., Falaki, A., Saghravanian, N., Nosratzehi, T., \& Pazouki, M. (2011). Clinical and histopathological analysis of oral Squamous cell carcinoma of young patients in Mashhad, Iran: A retrospective study and review of literature. Medicina Oral Patología Oral Y Cirugia Bucal, e473-e477. https://doi.org/10.4317/medoral.16.e473

Feller, L., \& Lemmer, J. (2012). Oral Squamous Cell Carcinoma: Epidemiology, Clinical Presentation and Treatment. Journal of Cancer Therapy, 3(04), 263-268. https://doi.org/10.4236/jct.2012.34037

Fiji Bureau of Statistics. (2012). 2007 Fiji Census of Population and Housing - Analytical Report. Suva: Fiji Bureau of Statistics.

Fiji population (2017) live - Country meters 2017. Retrieved 23 January 2018, from https://countrymeters.info/en/Fiji

Gaitan-Cepeda, L., Peniche-Becerra, A., \& Quezada-Rivera, D. (2011). Trends in frequency and prevalence of oral cancer and oral squamous cell carcinoma in Mexicans. A 20 years' retrospective study. Medicina Oral Patología Oral Y Cirugia Bucal, e1-5e. https://doi.org/10.4317/medoral.16.e1 
Gavidi, R., Cox, B., King, T., \& Rich, A. (2014). Epidemiological differences in oral squamous cell carcinoma in New Zealand and fiji. Pathology, 46, S9. https://doi.org/10.1097/01.PAT.0000443429.70369.cb

Glance, F. (2017). Fiji Bureau of Statistics - Fiji Bureau of Statistics. Retrieved 23 January 2022, from: http://www.statsfiji.gov.fj/

Hawley, N., \& McGarvey, S. (2015). Obesity and Diabetes in Pacific Islanders: the Current Burden and the Need for Urgent Action. Current Diabetes Reports, 15(5). https://doi.org/10.1007/s11892-015-0594-5

Kempen, P., Noorlag, R., Braunius, W., Moelans, C., Rifi, W., \& Savola, S. et al. (2015). Clinical relevance of copy number profiling in oral and oropharyngeal squamous cell carcinoma. Cancer Medicine, 4(10), 1525-1535. https://doi.org/10.1002/cam4.499

Lumukana R, King T (2003).Smoking and chewing habits of oral cancer patients in the Solomon Islands. Pacific Health Dialogue, 10, 41-44. PMID: 16276941

Mehrotra, R., \& Yadav, S. (2006). Oral squamous cell carcinoma: Etiology, pathogenesis and prognostic value of genomic alterations. Indian Journal of Cancer, 43(2), 60. https://doi.org/10.4103/0019-509X.25886

Meo, L., Phillips, D., \& Brough, R. (1996). Smoking in Viti Levu, Fiji. Pacific Health Dialogue, 3, 41-42

Muthu, K., Vaishnavi, V., \& Sivadas, G. (2018). Warning Signs and Symptoms of Oral Cancer and its Differential Diagnosis. Journal of Young Pharmacists, 10(2), 138-143. https://doi.org/10.5530/jyp.2018.10.32

Nagler, R., \& Dayan, D. (2006). The Dual Role of Saliva in Oral Carcinogenesis. Oncology, 71(1-2), 10-17. https://doi.org/10.1159/000100445

Nair, R., Odrovakavula, L., Mohammadnezhad, M., Raman Reddy, K., Gohil, D., \& Sami, S. (2021). Data Cleaning Needs and Issues: A Case Study of the National Reproductive Health Assessment (RHA) Data from Solomon Islands. Global Journal of Health Science, 13(3), 23. https://doi.org/10.5539/gjhs.v13n3p23

Neville, B., \& Day, T. (2002). Oral Cancer and Precancerous Lesions. CA: A Cancer Journal for Clinicians, 52(4), 195-215. https://doi.org/10.3322/canjclin.52.4.195

Nicolás Bolesina, Fabián L. Femopase, Silvia A. López de Blanc, Rosana A. Morelatto and María Alicia Olmos (2012). Oral Squamous Cell Carcinoma Clinical Aspects, Oral Cancer. Dr. Kalu U. E. Ogbureke (Ed.). https://doi.org/10.5772/32968

Markopoulos, A. (2012). Current Aspects on Oral Squamous Cell Carcinoma. The Open Dentistry Journal, 6(1), 126-130. https://doi.org/10.2174/1874210601206010126

Parkin, D. (2006). The evolution of the population-based cancer registry. Nature Reviews Cancer, 6(8), 603-612. https://doi.org/10.1038/nrc1948

Purwanto, D., Soedarsono, N., Reuwpassa, J., Adisasmita, A., Ramli, M., \& Djuwita, R. (2019). The prevalence of oral high-risk HPV infection in Indonesian oral squamous cell carcinoma patients. Oral Diseases, 26(1), 72-80. https://doi.org/10.1111/odi.13221

Rana, M., Kanatas, A., Herzberg, P., Khoschdell, M., Kokemueller, H., Gellrich, N., \& Rana, M. (2015). Prospective study of the influence of psychological and medical factors on quality of life and severity of symptoms among patients with oral squamous cell carcinoma. British Journal of Oral and Maxillofacial Surgery, 53(4), 364-370. https://doi.org/10.1016/j.bjoms.2015.01.019

Sargeran, K., Murtomaa, H., Safavi, S., Vehkalahti, M., \& Teronen, O. (2008). Survival after diagnosis of cancer of the oral cavity. British Journal of Oral and Maxillofacial Surgery, 46(3), 187-191. https://doi.org/10.1016/j.bjoms.2007.11.004

Screening.iarc.fr. (2018). A digital manual for the early diagnosis of oral neoplasia. Retrieved 22nd January, 2022, from https://screening.iarc.fr/atlasoral_list.php?cat=B2\&lang=1

Selvamani, M., Yamunadevi, A., Basandi, P., \& Madhushankari, G. (2015). Prevalence of oral squamous cell carcinoma of tongue in and around Davangere, Karnataka, India: A retrospective study over 13 years. Journal of Pharmacy and Bioallied Sciences, 7(6), 491. https://doi.org/10.4103/0975-7406.163511

Siakholak, F., Ghoncheh, M., Pakzad, R., Gandomani, H., Ghorat, F., \& Salehiniya, H. (2016). Epidemiology, incidence and mortality of oral cavity and lips cancer and their relationship with the human development index in the world. Biomedical Research and Therapy, 3(10), 872-888. https://doi.org/10.15419/bmrat.v3i10.129 
Silverman, S. Jr, Dillon, W. \& Fischbein, N. (1998). Diagnosis. In Silverman S. Jr ed. Oral Cancer (4th ed., pp. 41-66). Hamilton, Ontario, Canada: BC Decker Inc.

Sridharan, G., Ramani, P., Patankar, S., \& Vijayaraghavan, R. (2019). Evaluation of salivary metabolomics in oral leukoplakia and oral squamous cell carcinoma. Journal of Oral Pathology \& Medicine, 48(4), 299-306. https://doi.org/10.1111/jop.12835

Surveillance, Epidemiology, and End Results Program. (2022). Retrieved 23 January 2022, from https://seer.cancer.gov/

Warnakulasuriya, K., Robinson, D., \& Evans, H. (2003). Multiple primary tumours following head and neck cancer in southern England during 1961-98. Journal of Oral Pathology \& Medicine, 32(8), 443-449. https://doi.org/10.1034/j.1600-0714.2003.00179.x

\section{Copyrights}

Copyright for this article is retained by the author(s), with first publication rights granted to the journal.

This is an open-access article distributed under the terms and conditions of the Creative Commons Attribution license (http://creativecommons.org/licenses/by/4.0/). 